\title{
Tooth loss and alveolar remodeling in Sinosaurus triassicus (Dinosauria: Theropoda) from the Lower Jurassic strata of the Lufeng Basin, China
}

\author{
XING LiDa ${ }^{1,2^{*}}$, BELL Phil R ${ }^{3}$, ROTHSCHILD Bruce $\mathrm{M}^{4}$, RAN Hao ${ }^{5}$, ZHANG JianPing ${ }^{2}$, \\ DONG ZhiMing ${ }^{6}$, ZHANG Wei ${ }^{7} \&$ CURRIE Philip J ${ }^{1}$ \\ ${ }^{1}$ Department of Biological Sciences, University of Alberta, 11455 Saskatchewan Drive, Edmonton, Alberta T6G 2E9, Canada; \\ ${ }^{2}$ School of the Earth Sciences and Resources, China University of Geosciences, Beijing 100083, China; \\ ${ }^{3}$ Pipestone Creek Dinosaur Initiative, Clairmont, Alberta TOH OWO, Canada; \\ ${ }^{4}$ Division of Vertebrate Paleontology, Natural History Museum and Biodiversity Research Institute, University of Kansas, 1345 Jayhawk Boulevard, \\ Lawrence, KS 66045, USA; \\ ${ }^{5}$ Key Laboratory of Ecology of Rare and Endangered Species and Environmental Protection (Guangxi Normal University), Ministry of Education, \\ Guilin 541004, China; \\ ${ }^{6}$ Institute of Vertebrate Paleontology and Paleoanthropology, Chinese Academy of Sciences, Beijing 100044, China; \\ ${ }^{7}$ Department of Computer Engineering, Chengdu Electromechanical College, Chengdu 610072, China
}

Received November 25, 2012; accepted February 5, 2013; published online April 12, 2013

\begin{abstract}
Pathological or traumatic loss of teeth often results in the resorption and remodeling of the affected alveoli in mammals. However, instances of alveolar remodeling in reptiles are rare. A remodeled alveolus in the maxilla of the Chinese theropod Sinosaurus (Lower Jurassic Lower Lufeng Formation) is the first confirmed example of such dental pathology in a dinosaur. Given the known relationship between feeding behavior and tooth damage in theropods (teeth with spalled enamel, tooth crowns embedded in bone) and the absence of dentary, maxillary, and premaxillary osteomyelitis, traumatic loss of a tooth is most likely the cause of alveolar remodeling. Based on the extent of remodeling, the injury and subsequent tooth loss were non-fatal in this individual.
\end{abstract}

alveolar remodeling, paleopathology, Sinosaurus, Lufeng Basin, China

Citation: Xing L D, Bell P R, Rothschild B M, et al. Tooth loss and alveolar remodeling in Sinosaurus triassicus (Dinosauria: Theropoda) from the Lower Jurassic strata of the Lufeng Basin, China. Chin Sci Bull, 2013, 58: 1931-1935, doi: 10.1007/s11434-013-5765-7

Paleopathology is the study of disease and other abnormalities in the fossil record. Paleopathological investigations can reveal unique insights into the behavior, biology, and development of extinct animals. The main (actualistic) assumption in paleopathology is that modern processes that dictate an osseous response to trauma can be extrapolated to fossil taxa. Among theropod dinosaurs, injury-related trauma (bites, exostoses, fractures, infection, stress fractures) is the overriding cause of osteopathy; however, congenital abnormalities and arthritis (gout) have also been documented [1,2].

*Corresponding author (email: xinglida@gmail.com)
Few records of osseous abnormalities in Chinese dinosaurs have been documented. Formal reports include possible bacterial infection in the fibula of the basal ceratopsian Psittacosaurus [3], osteoarthritis in the theropods Caudipteryx, Confuciusornis and Microraptor [4], healed bite marks in Sinraptor [5], and a healed fracture in the theropod Yangchuanosaurus [6]. Possible palaeopathological phenomena have also been reported in the sauropods Fusuisaurus and Mamenchisaurus, although these were not described in detail [6].

Sinosaurus triassicus (="Dilophosaurus sinensis") is an Early Jurassic theropod characterized by twin hatchet-shaped crests similar to its North American relative Dilophosaurus [7,8]. In 2007, the Lufeng Dinosaurian Museum recovered 
an incomplete skull, and several postcranial fragments of a new specimen of Sinosaurus (ZLJT01) from the Lufeng Basin in Yunnan Province, China [9]. A detailed anatomical description and a phylogenetic analysis of ZLJT01 allow a critical assessment for the first time. A new phylogenetic analysis shows that Sinosaurus triassicus (="Dilophosaurus sinensis") is not the most basal dilophosaurid as was previously conculded by Smith et al. [10]; in contrast, Sinosaurus and the Cryolophosaurus emerge as more derived theropods; they were recovered as more closely related to Averostra then to Coelophysis bauri and Dilophosaurus wetherilli [9]. The right maxilla includes an abnormal, closed alveolus, the significance and possible etiology of which are considered in this paper.

ZLJT01 was discovered near Hewanzi Village, Ganchong Village Committees, Konglongshan Township, Lufeng County, Chuxiong Yi Autonomous Prefecture, Yunnan Province, China. The specimen includes parts of both premaxillae, both maxillae, dentary, nasal crests, occiput, and fragments of the postcranial skeleton. A detailed description of ZLJT01 and of Sinosaurus more broadly will be presented elsewhere. This paper details the palaeopathological features of the specimen.

\section{Geological setting}

The Lower Lufeng Formation of Yunnan Province, China preserves a diverse dinosaur assemblage, including ornithischians, prosauropods, sauropods, and theropods in a variety of fluvial, overbank, and lacustrine sediments [11]. The age of the Lower Lufeng Formation [12] was originally thought to be Late Triassic $[12,13]$. However, biostratigraphic correlations (both vertebrate and invertebrate) indicate an
Early Jurassic (Hettangian-Sinemurian) age $[11,14,15]$. The name "Lufeng Formation" has been restricted to what previously was the Lower Lufeng Formation, and the unit further subdivided into the Shawan (Hettangian) and Zhangjia'ao (Sinemurian) members [16]. However, this nomenclature has not been widely accepted [17]. ZLJT01 (Sinosaurus) comes from the lowermost (Shawan Member) portion of the Lower Lufeng Formation. Associated faunal elements include basal sauropodomorphs (Lufengosaurus, Yunnanosaurus), theropods (Lukousaurus), and the purported thyreophoran Bienosaurus.

Institutional abbreviations: KMV, Kunming City Museum, Kunming, Yunnan, China; LDM, Lufeng Dinosaurian Museum, Lufeng, Yunnan, China; SMNS, Staatliches Museum für Naturkunde Stuttgart, Stuttart, Germany; USNM, National Museum of Natural History, Washington, USA; ZLJ, Lufeng World Dinosaur Valley Park, Yunnan, China.

\section{Description}

The right maxilla of ZLJT01 is incomplete, lacking most of the posterodorsal process and the dorsal end of the jugal process (Figure 1(a)-(d)). Maxillary alveoli one to ten (mx1to mx10) are preserved in ZLJT01; however, the 10th alveolus is broken. Based on other Sinosaurus specimens, the complete maxilla likely had 13 (KMV 8701) or 14 (LDM-L10) tooth positions. Two broken teeth are preserved in the alveoli $\mathrm{mx} 3$ and $\mathrm{mx} 8$, and an incompletely erupted tooth crown is present in alveolus $\mathrm{mx} 5$. The remaining alveoli lack teeth, undoubtedly as a result of postmortem tooth loss.

In contrast with the other alveoli, alveolus mx6 is entirely closed by a layer of secondary bone (Figure 1(a)-(d)). In

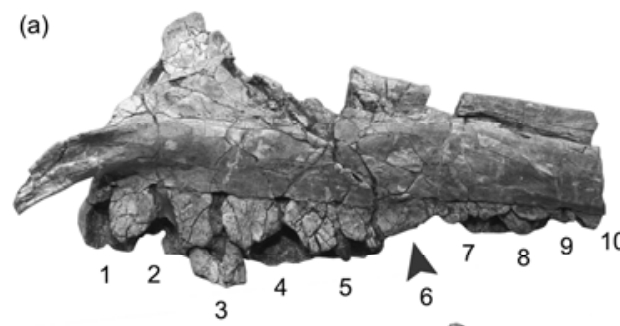

(c)

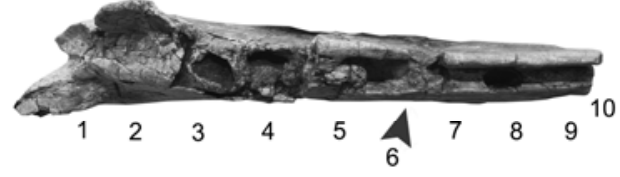

(d)
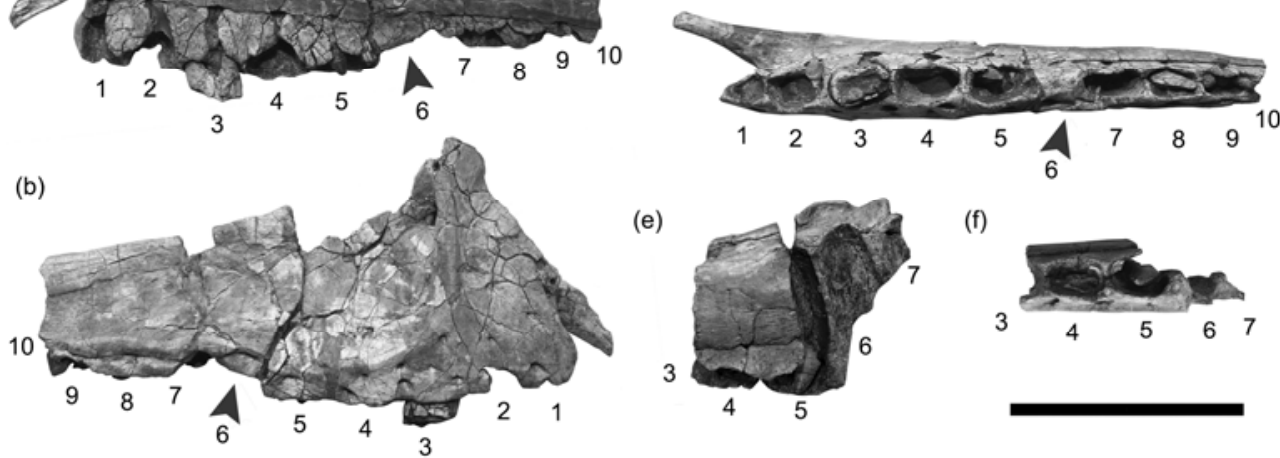

(e)

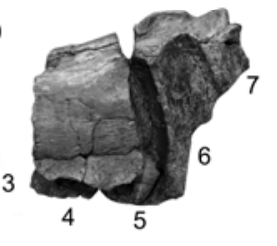

(f)
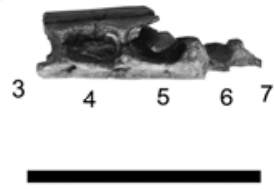

Figure 1 Palaeopathological characters of the right maxilla of ZLJT01 (Sinosaurus triassicus), in (a) medial; (b) lateral; (c) dorsal; (d) ventral views. Position of the abnormal alveolus mx6 is indicated by an arrowhead. Incomplete, normal left maxilla of ZLJT01 in (e) medial and (f) ventral aspects showing non-pathological alveolus mx6. Numerals in (a)-(f) refer to alveoli. Scale bar $=10 \mathrm{~cm}$. 
medial and lateral aspects, the rim of the alveolus lies dorsal to the horizontal plane formed by the other alveoli indicative of significant bone remodeling. This remodeling gives the jaw a distinct notch in mediolateral view at the sixth alveolus. The external surface of the new bone is smooth and the two interdental plates on either side of $\mathrm{mx} 6$ are fused to one another. An X-ray of the maxilla (Figure 2) clearly shows the outline of the original alveolus; however, the alveolar space is less radiolucent than the adjacent alveoli, which is indicative of secondary bone filling the alveolar space. This is further evidenced by the near total absence of pyrite growth ("pyrite rot") that pervades all other alveolar spaces (Figure 2). It is also noted that $m \times 7$ contains very little pyrite growth. No additional evidence of damage or remodeling to the bone surrounding mx6 was observed. The incomplete left maxilla from the same specimen, which includes alveoli mx3-7 (Figure 1(e)-(f)) has a normal alveolus for mx6, indicating tooth loss in the right maxilla was abnormal.

\section{Discussion and conclusions}

Dental abnormalities in theropods are infrequently reported in the literature. Broken teeth [18-20], and congenitally deformed teeth (such as the split carinae [1,2,18,21]) are among the most commonly documented abnormalities. Other potential congenital dental abnormalities include a "twisted" dentary in a hatchling Troodon $[1,22]$. Bite-marks and related traumas are also relatively common on the jaws and faces of a range of theropod taxa [1,5,23-26].

Dental abscesses, such as those reported in an unidentified hadrosaurid jaw [27] and in the captorhinid Labidosaurus [28], have yet to be identified in theropods. Abscesses form as a result of deep bacterial infections, resulting in osseous erosions associated with alveolar bone destruction and tooth loss.

When teeth are lost or removed in vivo, the bony socket remodels over time so that there is no longer an alveolus [29]. $\mathrm{X}$-ray evidence demonstrates the presence of an osseous

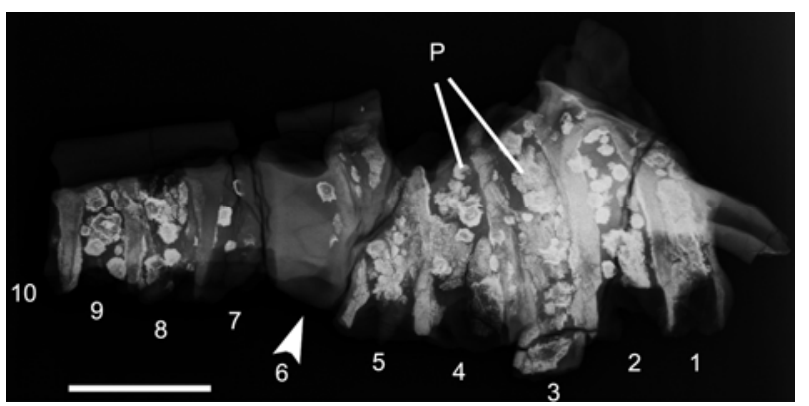

Figure 2 X-ray scan of the pathological right maxilla in ZLJT01 (Sinosaurus triassicus), in lateral aspect. Anterior is to the right. Arrowhead indicates pathological alveolus mx6. Pyrite growths $(\mathrm{P})$ show up as white discs. Note the near absence of pyrite in mx6. Scale bar $=5 \mathrm{~cm}$. infilling in the sixth alveolus of ZLJT01 typical of alveolar remodeling. This type of healing process following antemortem tooth loss is the first recorded for a dinosaur. Alveolus closure is extremely rare among living and fossil reptiles, having only been observed elsewhere in the fossil record in a specimen (SMNS 4379) of the phytosaur Nicrosaurus kapffi that has a single, closed alveolus in the right maxilla [30], which may have resulted from injury or failed replacement [31]. In contrast, alveolar remodeling is relatively common in extant primates, where tooth loss may be a result of feeding behavior [32-35]. Moreover, differences between the frequency of alveolar remodeling between mammalian and reptilian counterparts is likely also due to tooth replacement patterns; mammals have only a single set of replacement teeth, leaving alveolar closure as the only biological "option" following traumatic tooth avulsion. In contrast, reptiles (and dinosaurs) have continuous tooth replacement patterns, whereby a vacant alveolus is immediately supplied with a replacement tooth. Therefore alveolar remodeling would only appear to follow significant trauma and/or disruption of the normal tooth replacement patterns.

In vivo tooth loss can result from either pathological and/ or traumatic mechanisms. Pathological changes, such as periodontal disease (including periodontitis, alveolar osteomyelitis, and abscesses), may be responsible for destruction of the tooth root, the periodontal ligament, and/or the tooth socket itself, resulting in avulsion of the affected tooth [36]. This is accompanied by an osseous response to infection, including pus-draining sinuses (fistulae) and rapid bone growth with a characteristic disorganized texture. Such evidence of osteomyelitis was not observed in ZLJT01. Therefore a trauma-related (not pathological) mechanism for alveolar remodeling in ZLJT01 appears likely.

Traumatic tooth loss typically occurs as a result of a forceful impact to the tooth crown but may also be initiated by trauma to the alveolar margin or jaw [29,37]. Trauma can occur with or without damage to the surrounding bone and soft-tissue [38]. Although obvious indicators of dental trauma, such as retained tooth fragments and alveolar or jaw fracture, were not observed in ZLJT01, theropods frequently damaged teeth antemortem, presumably as a result of feeding activity [39]. Shed theropod teeth commonly encountered in ornithischian-dominated bonebeds similarly reflect antemortem tooth loss due to feeding behavior [40-42]. These are usually tooth crowns shed during the normal process of tooth replacement. However, virtually all show some evidence of damage, such as spalled, chipped enamel and breakage or wear that occurred before the crowns were shed. Broken tips of teeth are sometimes also found in the bonebeds, and rare examples of broken theropod teeth still embedded in prey bone demonstrate a clear relationship between feeding and tooth avulsion [25,43-45]. Although direct evidence of trauma (retained tooth fragments, healed fractures) was not observed in ZLJT01, traumatic tooth loss does not necessarily involve the surrounding bone [38]. 


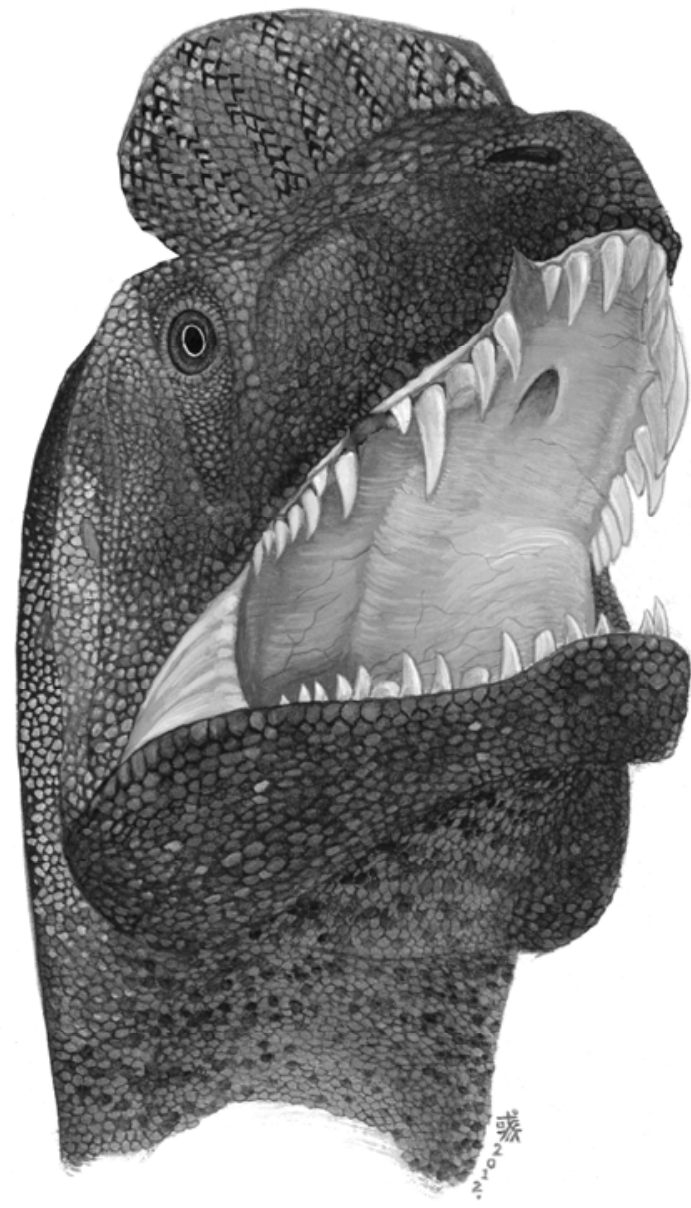

Figure 3 Life reconstruction of Sinosaurus triassicus with dental abnormality based on ZLJT01. Illustration by Liu Chenyu.

Given the known relationship between theropod feeding behavior and loss of replacement teeth, tooth loss in ZLJT01 was not likely a result of trauma to the tooth crown alone. In this case, the loss of the tooth may have been traumatic enough to damage the root of the tooth and the associated replacement (or germ) teeth. The changes associated with the dental plates are likely a result of resorption and remodeling following tooth loss, although traumatic loss to all or part of the dental plate cannot be discredited entirely. A similar condition was observed in a pathological Allosaurus dentary (USNM 2315; the holotype of "Labrosaurus ferox") that lacks the anterior four or five teeth. The alveoli were resorbed, resulting in a concave oral margin in lateral view giving the false impression of an edentulous jaw [46,47]. A possible traumatic etiology for the lost teeth in this specimen has been proposed [1].

The total closure of the alveolus in ZLJT01 and remodeling of the alveolar space indicate the animal survived for a lengthy period of time following the loss of the tooth. In human subjects, remodeling of the alveolar cavity occurs after the third month following injury $[29,48]$; however, this cannot be postulated to accurately reflect recovery time in any other species, particularly in an extinct dinosaur. As noted earlier, reptilian examples of alveolar remodeling are rare, and recovery times have not been studied in extant reptiles. Nevertheless, tooth loss in Sinosaurus clearly was non-fatal and ZLJT01 survived probably for months or even years (Figure 3). This finding adds to the known range of dental pathologies found in theropods and contributes to mounting evidence suggesting theropods were highly resilient to a broad spectrum of traumas and diseases $[26,49,50]$.

We thank Chairman Laigen Wang (World Dinosaur Valley Park, Yunnan Province, China) for providing ZLJT01 for study. Thanks to Julien D. Divay and W. Scott Persons IV (University of Alberta, Canada) for their critical comments and suggestions on an earlier version of the manuscript. Corwin Sullivan and an anonymous reviewer are thanked for their helpful reviews. Hua Jiang (Sichuan Provincial People's Hospital, Sichuan Province, China) provided advice on X-raying fossils. Eva Koppelhus (University of Alberta, Canada) also provided advice and support during the course of this project.

1 Molnar R E. Theropod paleopathology: A literature survey. In: Tanke D H, Carpenter K, eds. Mesozoic Vertebrate Life. Bloomington: Indiana University Press, 2001. 337-363

2 Rothschild B, Tanke D H. Theropod paleopathology, state-of-the-art review. In: Carpenter K, ed. The Carnivorous Dinosaurs. Bloomington: Indiana University Press, 2005. 351-365

3 Lü J C, Kobayashi Y, Lee Y N, et al. A new Psittacosaurus (Dinosauria: Ceratopsia) specimen from the Yixian Formation of western Liaoning, China: The first pathological psittacosaurid. Cret Res, 2007, 28: 272-276

4 Rothschild B, Zheng X T, Martin L. Osteoarthritis in the early avian radiation: Earliest recognition of the disease in birds. Cret Res, 2012, 35: $178-180$

5 Tanke D H, Currie P J. Head-biting behavior in theropod dinosaurs: Paleopathological evidence. Gaia, 2000, 15: 167-184

6 Xing L D, Dong H, Peng G Z, et al. A scapular fracture in Yangchuanosaurus hepingensis (Dinosauria: Theropoda). Geol Bull Chin, 2009, 28: 1390-1395

7 Hu S J. A new Theropoda (Dilophosaurus sinensis sp. nov.) from Yunnan, China. Vert PalAs, 1993, 31: 65-69

8 Dong Z M. Contributions of new dinosaur materials from China to dinosaurology. Mem Fukui Pref Dino Mus, 2003, 2: 123-131

9 Xing L D. Sinosaurus from southwestern China. MS Thesis (unpublished). Edmonton: University of Alberta, 2012

10 Smith N D, Makovicky P J, Hammer W R, et al. Osteology of Cryolophosaurus ellioti (Dinosauria: Theropoda) from the Early Jurassic of Antarctica and implications for early theropod evolution. Zool J linn Soc Lond . 2007. 151: 377-421

11 Luo Z X, Wu X C. The small tetrapods of the Lower Lufeng Formation, Yunnan, China. In: Fraser N C, Sues H D, eds. In the Shadow of the Dinosaurs: Early Mesozoic Tetrapods. Cambridge: Cambridge University Press, 1994. 251-270

12 Bien M N. "Red Beds" of Yunnan. Bull Geol Soc Chin, 1941, 21: 159-198

13 Young C C. The Lufeng saurischian fauna in China. Palaeontol Sin, 1951, New Series C 13: 1-96

14 Sheng S F, Chang L Q, Cai S Y, et al. The problem of the age and correlation of the red beds and the coal series of Yunnan and Szechuan. Acta Geol Sin, 1962, 42: 31-56

15 Sun A L, Cui K H. A brief introduction to the Lower Lufeng saurischian fauna (Lower Jurassic: Lufeng, Yunnan, People's Republic of China). In: Padian K, ed. The Beginning of the Age of Dinosaurs: Faunal Change Across the Triassic-Jurassic Boundary. Cambridge: Cambridge University Press, 1986. 275-278

16 Fang X S, Pang Q J, Lu L W, et al. Lower, Middle, and Upper Jurassic subdivision in the Lufeng region, Yunnan Province. In: Editorial 
Committee of the Proceedings of the Third National Stratigraphical Congress of China, eds. Proceedings of the Third National Stratigraphical Congress of China. Beijing: Geological Publishing House, 2000. 208-214

17 Barrett P M, Upchurch P, Wang X L. Cranial osteology of Lufengosaurus hueni Young (Dinosauria: Prosauropoda) from the Lower Jurassic of Yunnan, People's Republic of China. J Vert Paleontol, 2005, 25: 806-822

18 Farlow J O, Brinkman D L, Abler W L, et al. Size, shape, and serration density of theropod dinosaur lateral teeth. Mod Geol, 1991, 16: 161-198

19 Farlow J O, Brinkman D L. Wear surfaces on the teeth of tyrannosaurs. Paleontol Soc Spec Publ, 1994, 7. 165-175

20 Schubert B W, Ungar P S. Wear facets and enamel spalling in tyrannosaurid dinosaurs. Acta Palaeontol Pol, 2005, 50: 93-99

21 Erickson G M. Split carinae on tyrannosaurid teeth and implications of their development. J Vert Paleontol, 1995, 15: 268-274

22 Carpenter K. Baby dinosaurs from the Late Cretaceous lance and Hell Creek formations and a description of a new species of theropod. $\mathrm{U}$ Wyo Contr Geol, 1982, 20: 123-134

23 Wolff E D S, Varricchio D. Zoological paleopathology and the case of the tyrannosaurus jaw: Integrating phylogeny and the study of ancient disease. Geol Soc Am Abstr Prog, 2005, 37: 88

24 Rothschild B M, Molnar R E. Tyrannosaurid pathologies as clues to nature and nuture in the Cretaceous. In: Larson P, Carpenter K, eds. Tyrannosaurus rex, the Tyrant King. Bloomington: Indiana University Press, 2008. 287-306

25 Bell P R, Currie P J. A tyrannosaur jaw bitten by a confamilial: Scavenging or fatal agonism? Lethaia, 2009, 43: 278-281

26 Bell P R. Palaeopathological changes in a population of Albertosaurus sarcophagus from the Upper Cretaceous Horseshoe Canyon Formation of Alberta, Canada. Can J Earth Sci, 2010, 47: 1263-1268

27 Moodie R L. Dental abscesses in a dinosaur millions of years old, and the oldest yet known. Pac Dent Gaz, 1930, 38: 435-440

28 Reisz R, Scott D M, Pynn B R, et al. Osteomyelitis in a Paleozoic reptile: Ancient evidence for bacterial infection and its evolutionary significance. Naturwissenschaften, 2011, 98: 551-555

29 Morgan J. Observable stages and scheduling for alveolar remodeling following antemortem tooth loss. Dissertation for the Doctoral Degree (unpublished). Mainz: Johannes Gutenberg-Universität, 2011

30 Hungerbühler A. Heterodonty in the European phytosaur Nicrosaurus kapffi and its implications for the taxonomic utility and functional morphology of phytosaur dentitions. J Vert Paleontol, 2000, 20: $31-48$

31 Rothschild B M, Schultze H P, Peligrini R. Herpetological Osteopathology: Annotated Bibliography of Amphibians and Reptiles. Heidelberg: Springer-Verlag, 2012

32 Miles A E, Grigson C. Colyer's Variations and Diseases of the Teeth of Animals. Cambridge: Cambridge University Press, 1990

33 Stoner K E. Dental pathology in Pongo satyrus borneensis. Am J Phys Anthropol, 1995, 98: 307-321
34 Cuozzo F P, Sauther M L. Tooth loss, survival, and resource use in wild ring-tailed lemurs (Lemur catta): Implications for inferring conspecific care in fossil hominids. J Hum Evol, 2004, 46: 623-631

35 Cuozzo F P, Sauther M L. Severe wear and tooth loss in wild ringtailed lemurs (Lemur catta): A function of feeding ecology, dental structure, and individual life history. J Hum Evol, 2006, 51: 490-505

36 Hillson S. Recording dental caries in archaeological remains. Int J Osteoarchaeol, 2001, 11: 249-289

37 Lukacs J R. Dental trauma and antemortem tooth loss in prehistoric Canary Islanders: Prevalence and contributing factors. Int J Osteoarchaeol, 2007, 17: 157-173

38 Wright G, Bell A, McGlashan, G, et al. Dentoalveolar trauma in Glasgow: An audit of mechanism and injury. Dent Traumatol, 2007, 23: 226-231.

39 Schubert B W, Ungar P S. Wear facets and enamel spalling in tyrannosaurid dinosaurs. Acta Palaeontol Pol, 2005, 50: 93-99

40 Varricchio D, Horner J R. Hadrosaurid and lambeosaurid bonebeds from the Upper Cretaceous Two Medicine Formation of Montana: Taphonomic and biologic implications. Can J Earth Sci, 1993, 29: 997-1006

41 Ryan M J, Russell A P, Eberth D A, et al. The taphonomy of a Centrosaurus (Ornithischia: Ceratopsidae) bonebed from the Dinosaur Park Formation (Upper Campanian), Alberta, Canada, with comments on cranial ontogeny. Palaios, 2001, 16: 482-506

42 Eberth D A, Getty M. Ceratopsian bonebeds. In: Currie P J, Koppelhus E B, eds. Dinosaur Provincial Park: A Spectacular Ancient Ecosystem Revealed. Bloomington: Indiana University Press, 2005. 501-536

43 Currie P J, Jacobsen A R. An azhdarchid pterosaur eaten by a velociraptorine theropod. Can J Earth Sci, 1995, 32: 922-925

44 Buffetaut E, Martill D, Escuillié F. Pterosaurs as part of a spinosaur diet. Nature, 2004, 430: 33

45 Xing L D, Bell P R, Currie P J, et al. A sauropod rib with an embedded theropod tooth: Direct evidence for feeding behaviour in the Jehol group, China. Lethaia, 2012, doi: 10.1111/j.1502-3931.2012.00310.x

46 Marsh O. Principal characters of American Jurassic dinosaurs part VIII the order Theropoda. Am J Sci, 1884, 27: 411-416

47 Rothschild B M. Dinosaurian paleopathology. In: Farlow J O, Brett-Surman M K, eds. The Complete Dinosaur. Bloomington: Indiana University Press, 1997. 426-448

48 Schropp L, Wenzel A, Kostopoulos L, et al. Bone healing and soft tissue contour changes following single-tooth extraction: A clinical and radiographic 12-month prospective study. Int J Perio Rest Dent, 2003, 23: 313-323

49 Hanna R R. Multiple injury and infection in a sub-adult theropod dinosaur Allosaurus fragilis with comparisons to allosaur pathology in the Cleveland-Lloyd Dinosaur Quarry collection. J Vert Paleontol, 2002, 22: 76-90

50 Farke A A, O'Connor P M. Pathology in Majungasaurus crenatissimus (Theropoda: Abelisauridae) from the Late Cretaceous of Madagascar. J Vert Paleontol, 2007, 27(Suppl 2): 180-184

Open Access This article is distributed under the terms of the Creative Commons Attribution License which permits any use, distribution, and reproduction in any medium, provided the original author(s) and source are credited. 